\title{
ANALISIS FAKTOR PEMELIHARAAN BANGUNAN GEDUNG TERHADAP KENYAMANAN PEKERJA KANTOR
}

\author{
Mohammad Anantya Risanji, Raflis \\ Jurusan Teknik Sipil, Universitas Trisakti, Jakarta 11440 \\ E-mail : anantya1996@gmail.com
}

\begin{abstract}
ABSTRAK
Dalam dunia konstruksi pemeliharaan gedung merupakan suatu cara untuk mempertahankan fungsi gedung itu sendiri. Maka dari itu pemeliharaan bangunan gedung harus direncanakan pada saat pra-konstruksi, konstruksi, hingga masa pengoperasian. Agar memiliki suatu sistem yang jelas dan terencana. Hasilnya dari pemeliharaan gedung mampu memberikan rasa nyaman bagi pengguna gedung. Kenyamanan pada pekerja kantor dapat meningkatkan produktivitas pekerja. Oleh karena itu, perlu menganalisis seberapa besar pengaruh faktor pemeliharaan bangunan gedung terhadap kenyamanan pekerja kantor. Data primer penelitian ini dengan cara mendistribusikan kuesioner pada pekerja kantoran dengan jumlah 109 orang menggunakan metode random sampling. Data sekunder mengenai jumlah responden dan data pendukung lainnya di dapatkan bedasarkan studi literatur, peraturan dan jurnal. Pengolahan data dilakukan dengan menggunakan metode analisis berganda dengan bantuan software SPSS. Hasil analisa variabel-variabel pemeliharaan bangunan gedung secara simultan berpengaruh terhadap kenyamanan pekerja kantor sebesar 63,5\%. Sedangkan variabel pemeliharaan gedung yang paling dominan terhadap kenyamanan pekerja kantor adalah variabel pemeliharaan kebersihan ruangan dengan nilai beta sebesar 0,154 .
\end{abstract}

Kata kunci:

kenyaman, regresi linier berganda

\section{PENDAHULUAN}

\subsection{Latar Belakang}

Dalam dunia konstruksi pemeliharaan gedung merupakan suatu cara untuk mempertahankan fungsi gedung itu sendiri. Pelaksanaanya membutuhkan manajemen pemeliharan dan biaya pemeliharaan yang menunjang. Hasil dari pemeliharaan gedung mampu memberikan keamanan dan kenyamanan bagi pengguna gedung.

Pemeliharaan gedung seharusnya memiliki sistem yang jelas dan terencana. Pada kasus gedung yusuf panigoro belum adanya sistem pemeliharaan yang terencana dan teratur, tetapi hanya sekedar memperbaiki bagian yang rusak. Dengan kata lain, tidak adanya pemeliharaan rutin dan berkala yang direncanakan dengan baik [1]

Lingkungan kerja haruslah nyaman dimana dipengaruhi oleh kondisi fisik dan non fisik. Kondisi fisik yang berhubungan langsung dengan pekerja atau pegawainya seperti cahaya, suhu, suara, polusi, warna dan peralatan. Sedangkan untuk non fisik seperti hubungan antar atasan dan hubungan antar karyawan. Sebuah penelitian disalah satu hotel bahwa pengaruh dari kondisi fisik dan non fisik sebesar $32.7 \%$.
Sedangkan 67,3 \%dipengaruhi oleh variabel-variabel lain yan tidak dite liti. [2]

Jakarta sebagai Ibu Kota Negara Indonesia terdapat banyak bangunan gedung. Dimana beberapa gedung sudah berdiri dari puluhan tahun yang laludan memiliki fungsi sebagai aktivitas/kegiatan perkantoran. Gedung tersebut didisain sedemikian rupa agar penghuni atau pemakainya akan merasakan nyaman.

Menyadari akan bertambahnya umur bangunan gedung perkantoran sehingga perlunya menpertahankan kenyamanan yang sudah ada. Maka perlu mengetahui faktor yang mempengaruhi kenyamanan kegiatan pekerjaan kantor. Agar gedung yang sudah berdiri lama tetap memiliki rasa nyaman untuk penggunanya.

\subsection{Rumusan Masalah}

Dari latar belakang masalah yang ada diatas, rumusan masalah dalam penelitian ini bagaimanapengaruh pemeliharaan gedung perkantoran terhadap kenyamanan kegiatan pekerjaan kantor? 


\section{TINJAUAN PUS TAKA}

\subsection{Pemeliharaan Bangunan Gedung}

Pemeliharaan bangunan gedung adalah kegiatan menjaga keandalan bangunan gedung beserta prasarana dan sarananya agar bangunan gedung selalu laik fungsi (preventive maintenance).

\subsection{Perawatan Bangunan Gedung}

Perawatan bangunan gedung adalah kegiatan memperbaiki dan/atau mengganti bagian bangunan gedung, komponen, bahan bangunan, dan/atau prasarana dan sarana agar bangunan gedung tetap laik fungsi (currative maintenance).

\subsection{Kenyamanan}

Konsep tentang kenyamanan (comfort) sangat sulit untuk didefinisikan karena lebih merupakan penilaian responsif individu. Kenyamaan sebagai suatu keadaan telah terpenuhinya kebutuhan dasar manusia yang bersifat individual dan holistik. Dengan terpenuhinya kenyamanan dapat menyebakan perasaan sejahtera pada diri individu tersebut. Dalam suatu lingkungan kerja yang nyaman dipengaruhi oleh kondisi fisik dan kondisi non fisik.

\section{METODE PENELITIAN}

\subsection{Populasi dan Sampel}

Populasi penelitian adalah seluruh para pekerja kantoran di daerah DKI Jakarta. Sampel adalah wakil populasi yang diteliti. Pada penelitian ini teknik pengambilan sampel yang digunakan adalah teknik random sampling (sampel random). Sampel random adalah sampel yang diambil dari suatu populasi dan setiap anggota populasi mempunyai kesempatan yang sama untuk dipilih sebagai sampel. Untuk banyaknya jumlah sampel menggunakan rumus Slovin. Didapat ju mlah sampel minimu m 100 orang.

\subsection{Variabel Penelitian}

Terdiri dari variabel bebas dan variabel terkait sebagai berikut:

Tabel 1. Variabel Bebas

\begin{tabular}{|c|c|c|c|}
\hline $\mathrm{NO}$ & Variabel & Indikator & Refrensi \\
\hline \multirow{3}{*}{1} & \multirow{3}{*}{$\begin{array}{l}\text { Pemelih araan } \\
\text { Lan git-lan git } \\
\text { /Plafond }\left(\mathrm{X}_{1}\right)\end{array}$} & $\begin{array}{l}\text { Kebersihan } \\
\text { plafond }\end{array}$ & \multirow{2}{*}{$\begin{array}{l}\text { Permenpu no } \\
\text { 24/PRT/M/2008 } \\
{[3]}\end{array}$} \\
\hline & & Kondisi plafond & \\
\hline & & Material Plafond & $\begin{array}{l}\text { Indra Fernandi } \\
(2011)[4]\end{array}$ \\
\hline \multirow{4}{*}{2} & \multirow{4}{*}{$\begin{array}{l}\text { Pemeliharaan } \\
\text { Dinding }\end{array}$} & $\begin{array}{l}\text { Kebersihan } \\
\text { dinding }\end{array}$ & \multirow{4}{*}{$\begin{array}{l}\text { Permenpu no } \\
\text { 24/PRT/M/2008 } \\
\text { Indra Fernandi } \\
\text { (2011) }\end{array}$} \\
\hline & & $\begin{array}{l}\text { Warna catyang } \\
\text { digunakan pada } \\
\text { dinding }\end{array}$ & \\
\hline & & $\begin{array}{l}\text { Pemelihan } \\
\text { material dinding }\end{array}$ & \\
\hline & & Kondisi dinding & \\
\hline 3 & Pemeliharaan & Kondisi mebel & Permenpu \\
\hline
\end{tabular}

\begin{tabular}{|c|c|c|c|}
\hline & Mebel & Pemilihan & 24/PRT/M/2008 \\
\hline & & material mebel & Wulfram I \\
\hline & & $\begin{array}{l}\text { Kebersihan mebel } \\
\text { (bangku dan } \\
\text { meja kerja) }\end{array}$ & $\begin{array}{l}\text { Ervianto (2007) } \\
\text { [5] }\end{array}$ \\
\hline 4 & $\begin{array}{l}\text { Pemeliharaan } \\
\text { Sistem }\end{array}$ & $\begin{array}{l}\text { Pencahay aan } \\
\text { lampu y ang } \\
\text { memadai }\end{array}$ & $\begin{array}{l}\text { Permenpu no } \\
\text { 24/PRT/M/2008 } \\
{[3]}\end{array}$ \\
\hline & Peneran gan & $\begin{array}{l}\text { Jenis lampu yang } \\
\text { digunakan }\end{array}$ & $\begin{array}{l}\text { Indra Fernandi } \\
(2011) \text { [4] }\end{array}$ \\
\hline & & $\begin{array}{l}\text { Ketersedian Air } \\
\text { Conditioning }(\mathrm{AC})\end{array}$ & $\begin{array}{lr}\text { Permenpu no } \\
24 / \text { PRT/M/2008 }\end{array}$ \\
\hline 5 & $\begin{array}{l}\text { Pemeliharaan } \\
\text { Tata Udara }\end{array}$ & $\begin{array}{l}\text { Kelembaban } \\
\text { udara }\end{array}$ & $\begin{array}{l}{[3]} \\
\text { Indra Fernandi }\end{array}$ \\
\hline & & Kondisi $A C$ & (2011) [4] \\
\hline & Pemeliharaan & $\begin{array}{l}\text { Kerapihan } \\
\text { penataan kursi, } \\
\text { meja dll }\end{array}$ & $\begin{array}{l}\text { Permenpu no } \\
\text { 24/PRT/M/2008 }\end{array}$ \\
\hline 6 & Kebersihan & Kebersihan lantai & In] \\
\hline & & $\begin{array}{l}\text { Ketersedian bak } \\
\text { sampah }\end{array}$ & $\begin{array}{l}\text { Indra Fernandi } \\
\text { (2011) [4] }\end{array}$ \\
\hline 7 & $\begin{array}{l}\text { Pemeliharaan } \\
\text { Kualitas } \\
\text { Ruangan dari } \\
\text { Efektivitas }\end{array}$ & \begin{tabular}{l}
\multicolumn{2}{l}{ kemampuan } \\
ruangan meredam \\
suara-suara dan \\
kebisingan dari \\
luar
\end{tabular} & $\begin{array}{l}\text { Indra Fernandi } \\
\text { (2011) [4] }\end{array}$ \\
\hline & Akustik & $\begin{array}{l}\text { Pemelihan } \\
\text { interior }\end{array}$ & \\
\hline 8 & Pemeliharaan & $\begin{array}{l}\text { Kondisi } \\
\text { transpotasi } \\
\text { vertikal }\end{array}$ & $\begin{array}{l}\text { Permenpu no } \\
\text { 24/PRT/M/2008 }\end{array}$ \\
\hline & $\begin{array}{l}\text { Transpotasi } \\
\text { Vertikal }\end{array}$ & $\begin{array}{l}\text { Kebersihan } \\
\text { transpotasi } \\
\text { vertikal }\end{array}$ & $\begin{array}{l}{[3]} \\
\text { Indra Fernandi } \\
\text { (2011) }[4]\end{array}$ \\
\hline & & Jumlah CCTV & $\begin{array}{ll}\text { Permenpu } & \text { no }\end{array}$ \\
\hline 9 & $\begin{array}{l}\text { Pemeliharaan } \\
\text { Sistem } \\
\text { Elektronika }\end{array}$ & Kualitas internet & $\begin{array}{l}\text { [3] } \\
\text { Wulfram I } \\
\text { Ervianto (2007) } \\
\text { [5] }\end{array}$ \\
\hline & Pemeliharaan & $\begin{array}{l}\text { Kebersihan } \\
\text { peralatan sanitair }\end{array}$ & $\begin{array}{l}\text { Permenpu no } \\
\text { 24/PRT/M/2008 } \\
{[3]}\end{array}$ \\
\hline 10 & $\begin{array}{l}\text { Sistem } \\
\text { Sanitair }\end{array}$ & $\begin{array}{l}\text { Jumlah peralatan } \\
\text { sanitair }\end{array}$ & Wulfram I \\
\hline & & $\begin{array}{l}\text { Kondisi peralatan } \\
\text { sanitair }\end{array}$ & $\begin{array}{l}\text { Ervianto }(2007) \\
\text { [5] }\end{array}$ \\
\hline & & Kebersihan taman & $\begin{array}{ll}\text { Permenpu } & \text { no }\end{array}$ \\
\hline 11 & Pemeliharaan & $\begin{array}{l}\text { Bidang } \\
\text { Perkerasan }\end{array}$ & $\begin{array}{l}\text { 24/PRT/M/2008 } \\
\text { [3] }\end{array}$ \\
\hline & & Vegetasi taman & $\begin{array}{l}\text { Jori, Octavianus } \\
\text { (2015) [6] }\end{array}$ \\
\hline & & Kebersihan kusen & Permenpu no \\
\hline & & Kondisi kusen & 24/PRT/M/2008 \\
\hline 12 & Pemeliharaan & Material kusen & {$[3]$} \\
\hline 12 & Kusen & $\begin{array}{lr}\begin{array}{l}\text { Kondisi } \\
\text { engsel }\end{array} & \text { Kunci, } \\
\text { grendel } & \text { dan }\end{array}$ & $\begin{array}{l}\text { Wulfram I } \\
\text { Ervianto (2007) } \\
\text { [5] }\end{array}$ \\
\hline & & $\begin{array}{ll}\text { Kondisi } & \text { kaca } \\
\text { gedung }\end{array}$ & Permenpu no \\
\hline 13 & $\begin{array}{l}\text { Pemeliharaan } \\
\text { Kaca }\end{array}$ & $\begin{array}{l}\text { Kebersihan kaca } \\
\text { gedung }\end{array}$ & $\begin{array}{l}\text { 24/PRT/M/2008 } \\
{[3]}\end{array}$ \\
\hline & & $\begin{array}{ll}\text { Jenis } & \text { kaca } \\
\text { gedung }\end{array}$ & $\begin{array}{l}\text { Jor, Uctavianus } \\
\text { (2015) [6] }\end{array}$ \\
\hline
\end{tabular}


Tabel 2: Variabel Terikat

\begin{tabular}{|c|c|c|c|}
\hline NO & Variabel & Indikator & Refrensi \\
\hline 1 & Aktivitas & $\begin{array}{c}\text { Pekerja dalam } \\
\text { melakukan } \\
\text { aktivitasnya } \\
\text { secara lancar atau } \\
\text { bebas }\end{array}$ & $\begin{array}{c}\text { Heidjrachman } \\
\text { Ranupandojo } \\
\text { \& Suad Husnan } \\
(1994)[7]\end{array}$ \\
\hline 2 & Kinerja & $\begin{array}{c}\text { Meningkatan } \\
\text { kinerja dari } \\
\text { pegawai atau } \\
\text { karyawan }\end{array}$ & $\begin{array}{c}\text { Nitisemito } \\
\text { (1998) }\end{array}$ \\
\hline
\end{tabular}

\subsection{Teknik Analisis Data}

\subsubsection{Uji Vali ditas}

Validitas merupakan sifat yang menunjukkan adanya kemampuan suatu alat ukur untuk mengungkapkan sesuatu yang menjadi pokok sasaran penelitian. Semakin tinggi validitas suatu alat ukur tersebut maka akan semakin tinggi kemungkinan untuk mengenai pokok sasarannya.

\subsubsection{Uji Relibilitas}

Realibilitas merupakan ukuran suatu kestabilan dan konsistensi responden dalam menjawab hal yang berkaitan dengan konstruk-konstruk pertanyaan yang merupakan dimensi suatu variabel dan disusun dalam suatu bentuk kuesioner.

\subsubsection{Uji Normalitas}

Uji normalitas bertujuan untuk menguji apakah variabel pengganggu atau residual dalam model regresi telah terdistribusi normal atau tidak. Model regresi yang diharapkan adalah yang memiliki nilai residual terdistribusi normal atau mendekati normal.

\subsubsection{Uji Autokorelasi}

Uji autokorelasi digunakan untuk menguji apakah dalam suatu model regresi linier terjadi korelasi antar kesalahan pengganggu (residual) pada periode $t$ dengan kesalahan pada periode t-1 (sebelu mnya).

\subsubsection{Uji Multikolinearitas}

Uji multikolinearitas digunakan untuik menguji model apakah terjadi hubungan yang sempurna atau hampir sempurna antara variabel bebas, sehingga sulit untuk memisahkan pengaruh antara variabel-variabel tersebut secara individu terhadap variabel terikat.

\subsubsection{Uji Heteroskedastisitas}

Uji heteroskedastisitas digunakan untuk menguji apakah dalam model regresi terjadi ketidaksamaan variabel dari residual satu pengamatan ke pengamatan lain.

\subsubsection{Uji T}

Uji $\mathrm{T}$ dikenal dengan uji parsial, digunakan untuk menguji secara parsial masing-masing variabel. Hasil uji $\mathrm{T}$ dapat dilihat pada tabel coefficient pada kolom sig (significance).

\subsubsection{Uji F}

Uji $\mathrm{F}$ digunakan untuk mengetahui pengaruh variabel bebas secara bersama-sama (simultan) terhadap variabel terikat.

\subsubsection{Uji $\mathbf{R}^{2}$}

Pengujian koefisien determinasi atau yang disebut uji $\mathrm{R}^{2}$ bertujuan untuk mengukur seberapa jauh kemampuan model dapat menjelaskan variabelvariabel terikat.

\section{HAS IL DAN PEMBAHASAN}

\subsection{Latar Belakang Res ponden}

Berdasarkan analis is deskriptif profil responden, dapat diketahui bahwa jumlah responden berjenis kelamin laki-laki 54\% dan perempuan $46 \%$. Berdasarkan pengalaman kerja presentase $>5$ tahun sebesar $47 \%$, lalu $<2$ tahun sebesar $37 \%$ dan 2-5 tahun sebesar $16 \%$. Tingkat pendidikan responden didominasi S1 sebesar $72 \%$ dan terdapat 7 profesi, dimana yang paling dominan adalah engineer sebesar $21 \%$.

\subsection{Uji Validitas}

Melalui uji validitas, peneliti mendapatkan bahwa indikator-indikator yang digunakan dapat dinyatakan valid karena $\mathrm{r}$ hitung > $\mathrm{r}$ tabel. Indikator yang valid dapat menggambarkan setiap variabelnya, sehingga tidak ada indikator yang dibuang, maka semua indikator di atas dapat digunakan untuk analis is lebih lanjut.

\subsection{Uji Reabilitas}

Berdasarkan uji reabilitas bahwa kuesioner ini dengan rata-rata sangat reliabel atau reliable karena memiliki nilai Cronbach's Alpha-nya lebih besar dari 0,8 atau 0,6 . Untuk itu, maka penelitian yang terkait dengan variabel dan indikator dapat dianalis is lebih lanjut.

\subsection{Uji Normalitas}

Pada uji normalitas Kolgomorov-Smirnov didapat nilai signifikansi sebesar $0.698>0.05$. Sehingga menunjukkan bahwa sampel berasal dari populasi yang terdis tribusi normal. 


\subsection{Uji Multikolinearitas}

Bedasarkan Uji Multikolinearitas dimana hasil uji menunjukkan bahwa masing-masing variabel bebas mempunyai nilai tolerance $>0,1$ dan VIF $<10$, art inya pada model regresi bebas dari terjadinya multikolinearitas.

\subsection{Uji Heteroskedastitas}

Bedasarkan hasil uji heteroskedastisitas yang menunjukkan bahwa tidak terdapat pola tertentu pada grafik scatterplot serta titik-titik yang menyebar diatas dan dibawah angka 0 pada sumbu $\mathrm{Y}$, artinya model regresi telah memenuhi asumsi heteroskedastisitas .

\subsection{Uji Autokorelasi}

Setelah dilakukan uji autokorelasi diperoleh nilai $d_{w}$ yang kemudian dibandingkan dengan beberapa nilai lainnya. Nilai $d_{w}=2,025$ sementara nilai $d_{u}=1,9595$ dan $4-d_{u}=2,0405$, dapat dilihat bahwa nilai $d_{w}$ masih terletak diantara $d_{u}$ dan $4-d_{u}$ sehingga pada model regresi tidak terjadi autokorelasi.

\subsection{Analisis Regresi Berganda}

Berdasarkan hasil analisis perhitungan statistik regresi linier berganda dapat diketahui bentuk persamaan regresinya adalah:

$$
\begin{aligned}
Y=2.201+0.105 X_{1}+0,061 X_{2}+0,102 X_{3} \\
+0.91 X_{4}+0.104 X_{5}+0.154 X_{6} \\
+0.86 X_{7}+0.142 X_{8}+0.097 X_{9} \\
+0.100 X_{10}+0.100 X_{11} \\
+0.048 X_{12}+0.049 X_{13}
\end{aligned}
$$

\subsection{Koefisien Regrasi Secara Parsial (Uji t)}

Pada pengujian koefisien regrasi secara parsial terhadap variabel bebas didapat nilai Sig. $<0,05$ dan nilai $t_{\text {hitung }}>t_{\text {tabel }}$ maka $\mathrm{H}_{0}$ ditolak, sehingga dapat disimpulkan bahwa variabel-variabel pemeliharaan bangunan gedung secara parsial berpengaruh signifikan terhadap kenyamanan pekerja kantor.

\subsection{Koefisien Regresi Secara Simultan (Uji F)}

Pada uji F didapat Nilai Sig. $<0,05$ dan nilai $F_{\text {hitung }}>$ $\mathrm{F}_{\text {tabel }}$, maka $\mathrm{H}_{0}$ ditolak, sehingga dapat disimpulkan bahwa variabel-variabel pemeliharaan bangunan gedung secara simultan berpengaruh signifikan terhadap kenyamanan pekerja kantoran.

\subsection{Analisis Koefisien Determinasi $\left(\mathbf{R}^{2}\right)$}

Menunjukkan hasil analisis regresi berganda dengan nilai Adjusted $R$ Square sebesar 0,635. Hal tersebut dapat diartikan bahwa komponen pemeliharaan gedung $(\mathrm{X})$ mempunyai pengaruh atau mampu menjelaskan variabel kenyamanan pekerja kantoran (Y) sebesar 63,5\% variabel bebas lain yang tidak tercantum dalam sedangkan sisanyasebesar $36,5 \%$ merupakan variabel bebas lain yang tidak tercantum dalam penelitian in $\mathrm{i}$.

\subsection{Hasil Pembahasan dan Analisis}

Hasil uji $\mathrm{R}^{2}$ menunjukkan variabel pemeliharaan bangunan gedung memiliki pengaruh terhadap variabel kenyamanan pekerja kantoran (Y) dengan presentase sebesar $63,5 \%$. Sehingga tidak selalu faktor bangunan gedung berpengaruh dominan karena terdapat faktor lain. Hal ini terlihat pengaruh bangunan gedung pada fungsi kantor dan rumah sakit memiliki yang dominan karena me miliki fungsi yang sama sebagai fasilitas umum. Sehingga penggunanya memerlukan lingkungan fisik yang baik agar terasa nyaman. Berikut pada Tabel 3 adalah urutan variabel dominan yang mempengaruhi tingkat kenyamanan:

Tabel 3. Urutan Variabel Dominan

\begin{tabular}{|c|l|c|}
\hline No & \multicolumn{1}{|c|}{ Variabel } & B \\
\hline 1 & Pemeliharaan Kebersihan Ruangan & 0.154 \\
\hline 2 & Pemeliharaan Transportasi Vertikal & 0.142 \\
\hline 3 & Pemeliharaan Plafond & 0.105 \\
\hline 4 & Pemeliharaan Tata Udara & 0.104 \\
\hline 5 & Pemeliharaan Mebel & 0.102 \\
\hline 6 & Pemeliharaan Sanitair & 0.100 \\
\cline { 2 - 3 } & Pemeliharaan Tata Luar & 0.100 \\
\hline 8 & Pemeliharaan Elektronika & 0.097 \\
\hline 9 & Pemeliharaan Sistem Penerangan & 0.091 \\
\hline 10 & Pemeliharaan Ruangan Akustik & 0.086 \\
\hline 11 & Pemeliharaan Dinding/Partisi & 0.061 \\
\hline 12 & Pemeliharaan Kaca Gedung & 0.049 \\
\hline 13 & Pemeliharaan Kusen & 0.048 \\
\hline
\end{tabular}

\section{KES IMPULAN DAN SARAN}

\subsection{Kesimpulan}

Berdasarkan serangkaian tahapan penelitian yang telah dilakukan pada pengaruh pemeliharaan bangunan gedung terhadap kenyamanan pekerja kantoran maka dapat ditarik kesimpulan sebagai berikut: 
1. Variabel komponen pemeliharaan gedung (X) secara simultan berpengaruh signifikan terhadap variabel kenyamanan pekerja kantor $(\mathrm{Y})$ dengan nilai koefisien determinasi sebesar 0.635 . Hal ini menjelaskan bahwa ketiga variabel tersebut mempunyai pengaruh sebesar $63,5 \%$ terhadap variabel kenyamanan pekerja kantoran, sedangkan sisanya sebesar $36,5 \%$ dipengaruhi oleh variabel bebas lain yang tidak tercantum dalam penelitian ini.

2. Variabel pemeliharan kebersihan ruangan merupakan variabel yang paling dominan mempengaruhi kenyamanan pekerja kantor dibandingkan dengan variabel yang lain.

\subsection{Saran}

Berdasarkan hasil penelitian yaitu terdapatnya pengaruh pemeliharaan bangunan gedung terhadap kenyamanan pekerja kantor maka pemilik gedung diharapkan dapat meningkatkan pemeliharaan gedung secara maksimal sehingga dapat meningkatkan kenyamanan pekerja kantoran. Untuk penelitian berikutnya dapat di teliti lebih dalam dengan menambahkan indikator setiap variabel untuk mendapatkan hasil yang lebih akurat.

\section{DAFTAR PUSTAKA}

[1] Isamulia, Lunie. 2012. Kajian Kegiatan Pemeliharaan bangunan Dalam Konteks Asset Management Studi Kasus: Gedung Yusuf Panigoro Institut Teknologi Bandung

[2] Tanayo, Kevin dan Yudha, Teddy W. 2015. Pengaruh Lingkungan Kerja Karyawan Hotel Majapahit Surabaya

[3] Anonim, 2008, Peraturan Menteri Pekerjaan UmumNo.24/PRT/M/2008 tentang Pedoman Pemeliharaan dan Perawatan Gedung, Departemen Pekerjaan Umum, Jakarta

[4] Fernandi, Indra. 2011. Kajian Pengaruh Faktor-Faktor Pemeliharaan Bangunan Gedung Perkantoran Terhadap Keny amanan Kegiatan Perkuliahan

[5] Ervianto, I. Wulfram. 2007. Studi Pemeliharaan Bangun an Gedung (Studi Kasus: Gedung Kampus)

[6] Jori, Octavianus. 2015. Studi Pemeliharaan Gedung "Studi Kasus Pada Bagian Manajemen Pemeliharaan Gedung Universitas Gajah Mada Yogyakarta"

[7] Heidjrachman Ranupandojo \& Suad Husnan, 1994, Manajemen Personalia, BPFE, Universitas Gajah Mada, Edisi Ke Empat, Yogy akarta 